\title{
A Rare Case of Foreign Body Bronchus: A Case Report
}

\author{
Irfan Iqbal • M. Lateef • Asif A. Wani • \\ Sheikh Rafiq
}

Received: 17 October 2008/Accepted: 28 March 2009/Published online: 28 May 2011

(C) Association of Otolaryngologists of India 2011

\begin{abstract}
Foreign body inhalation is commonly seen in children who need to be treated promptly and immediately otherwise it leads to complications. We here report a rare case of foreign body detached part of metallic tracheostomy tube in left main bronchus.
\end{abstract}

Keywords Foreign body bronchus - Tracheostomy tube

\section{Introduction}

Inhalation of foreign body by no means is an uncommon occurrence. The type of foreign bodies is almost endless and their enumeration is unnecessary. Foreign body can only enter the air passage if there is some interference with normal reflex action such as sudden inspiration while eating, playing, fright or laughter. These accidents are more common in children. Foreign body remains in trachea when its size is greater than the tracheal lumen or in cases if sharp foreign bodies when it gets impacted.

\section{Case Report}

10 year old female who had undergone tracheolaryngoplasty for sub-glottic stenosis and was put on metallic tracheostomy tube for last 3 years. She was brought to ORL, HNS Government Medical College Srinagar by her parents when they noticed in the morning that her tube was not present at the tracheostomy site. Patient was not in distress,

I. Iqbal $(\bowtie) \cdot$ M. Lateef · A. A. Wani · S. Rafiq

Department of ENT, HNS, Government Medical College,

Srinagar, Jammu and Kashmir, India

e-mail: drirfan2007@gmail.com she had no stridor and she went a routine X-ray chest in which the tracheotomy tube was found in left main bronchus (Fig. 1, with $\rightarrow$ ). Auscultation did not reveal any signs of obstruction and her other ENT and routine tests were normal. Bronchoscopy was done by passing the bronchoscope through the tracheotomy and foreign body (tracheotomy tube, Fig. 2) was removed which was hollow and rusted because of which patient had no difficulty in breathing as the air could easily move in and out of hollow tube. The tube had rusted and which had resulted in its detachment from the flanges of tracheostomy tube.

\section{Discussion}

Tracheobronchial foreign bodies especially in children and infants are fraught with respiratory obstruction and can even lead to death. Majority of foreign bodies come to rest in right main bronchus because of it being wider than the left but in young children there is a more equal distribution between the bronchi of two sides.

Different types of foreign bodies are encountered in bronchus including pen-caps, whistles, safety pins, vegetative foreign bodies, metallic pieces and seeds of different fruits. If these are not removed immediately they will result in death of the patient.

The prognosis and outcome depends on multiple factors like age of the patient, presentation, surgical and anaesthetic skills.

Management approach has to be systematic. Preoperative radiological assessment followed by rapid intervention by skilled bronchoscopists usually results in favourable outcome.

Metallic tracheostomy tubes are not used these days, except rarely for infants. When used these should be 

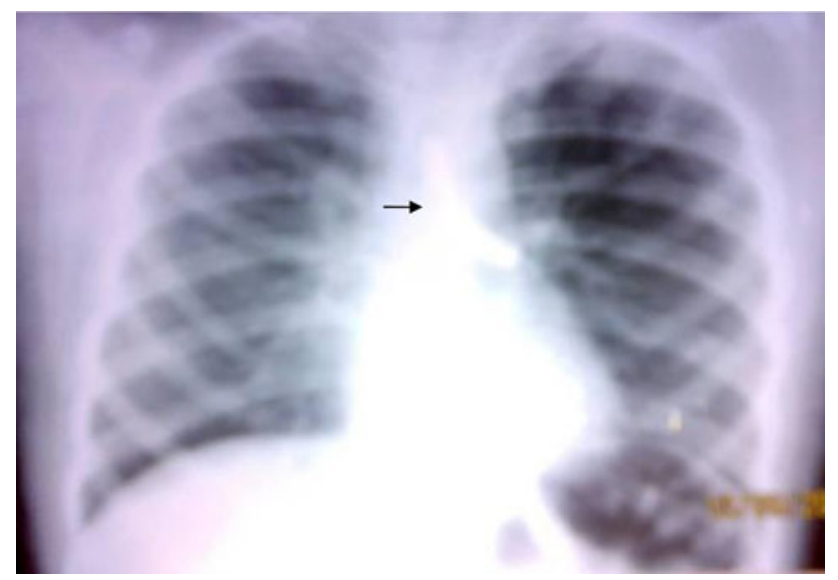

Fig. 1 X-ray chest showing foreign body left main bronchus

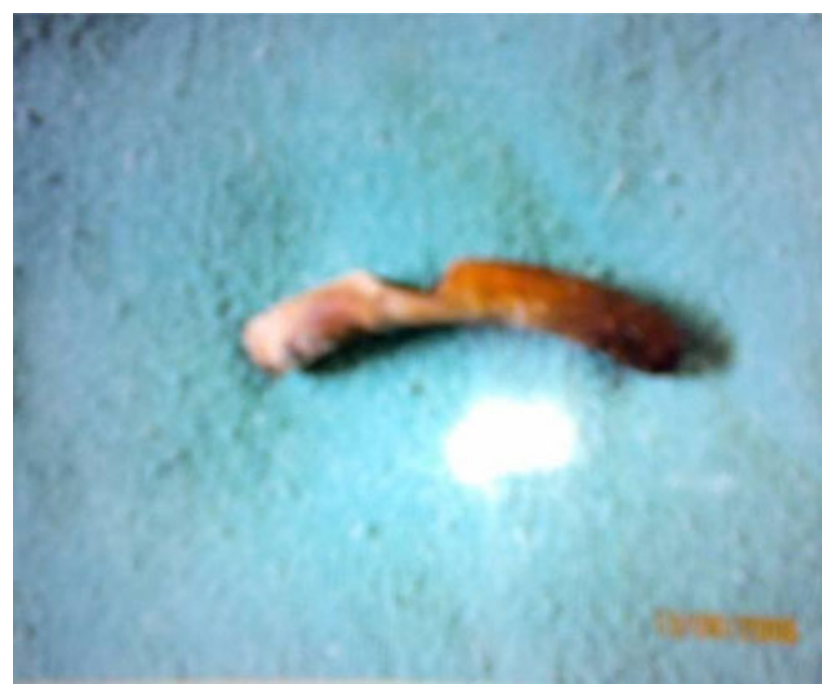

Fig. 2 Photograph of foreign body (fractured tracheostomy tube) after removal replaced regularly. The case under study was unusual in many respects, like the tracheostomy tube was worn out and rusted and had been in use over a long time and also the tube was still in use even after its flanges had broken down [1-5].

\section{References}

1. Gupta IP, Sood VP (1967) Foreign body in the air passages. Indian J Otolaryngol 19:173-174

2. Brooks JW (1972) Foreign bodies in the air and food passage. Ann Surg 175:720-732

3. Al-Naaman YD, Al-Ani MS, Al-Ani HR (1975) Non-vegetative foreign bodies in the bronchopulmonary tract in children. J Laryngol Otol 89:289-297

4. Panda G (1976) Iron nails in the tracheobronchial tree. Indian J Otolaryngol 28:192-193

5. Narayanan RK, Sharma PS (1977) Foreign bodies in the tacheobronchial tree. Indian Paediatr 14:133-134 